Reactance, morality, and disgust: The relationship between affective dispositions and compliance with official health recommendations during the COVID-19 pandemic.

Rodrigo Díaz ${ }^{12} \&$ Florian Cova ${ }^{3}$

${ }^{1}$ Institute of Philosophy, University of Bern, Bern, Switzerland, 3012 Bern, Switzerland

${ }^{2}$ Centre for Research in Ethics, University of Montreal, Montreal, Canada, 2910 Montreal, Canada

${ }^{3}$ Philosophy Department \& Swiss Center for Affective Sciences, University of Geneva,

Geneva, Switzerland, 9 Chemin des Mines, 1202 Geneva, Switzerland

Correspondence: rodrigo.diaz@philo.unibe.ch 


\section{Reactance, morality, and disgust: The relationship between affective dispositions and compliance with official health recommendations during the COVID-19 pandemic.}

Emergency situations require individuals to make important changes in their behavior. In the case of the COVID-19 pandemic, official recommendations to avoid the spread of the virus include costly behaviors such as self-quarantining or drastically diminishing social contacts. Compliance (or lack thereof) with these recommendations is a controversial and divisive topic, and lay hypotheses abound regarding what underlies this divide. This paper investigates which cognitive, moral, and emotional traits separate people who comply with official recommendations from those who don't. In four studies (three pre-registered) on both U.S. and French samples, we found that individuals' self-reported compliance with official recommendations during the COVID-19 pandemic was partly driven by individual differences in moral values, disgust sensitivity, and psychological reactance. We discuss the limitations of our studies and suggest possible applications in the context of health communication.

Keywords: Reactance, Morality, Disgust, Coronavirus, COVID-19

Data, materials, and analysis scripts are available at https://osf.io/z74ap/

\section{Introduction}

During the COVID-19 pandemic, governments and official organizations worldwide have implemented a series of nonpharmaceutical health measures. These measures aim to slow the spread of the pandemic while pharmaceutical means to fight the virus are developed and made accessible to the population. Some of these measures (e.g., travel restrictions, business closures, curfews) are imposed by law and enforced by the police. However, other measures 
(e.g., avoiding contact, washing hands, coughing on one's elbow) are mere recommendations and rely on individuals' autonomous choices.

Compliance with health recommendations during the COVID-19 pandemic is a divisive topic. Some individuals eagerly endorse these recommendations, while others frontally reject them. Lay hypotheses abound regarding the cognitive and affective traits underlying this divide. Are those who comply with health recommendations moral or fearful? Are the ones who reject recommendations protectors of freedom or conspiracists? Such hypotheses can be found in the media (see, e.g., Bhanot, 2020; Kelland \& Revell, 2020; Wiest, 2020) and are sometimes endorsed as correct by laypeople. However, only empirical evidence will allow us to distinguish between true and false explanations.

This paper investigates the impact of several putatively relevant factors on individuals' (lack of) compliance with health recommendations during the COVID-19 pandemic. All factors are considered at the level of psychological traits (vs. states). This allows us to use wellvalidated inventories to measure each factor and ensure the accuracy of our measurement methods. The traits we investigated can be divided into three categories: (i) cognitive and epistemic dispositions, (ii) moral values, and (iii) affective dispositions. ${ }^{1}$

\subsection{Cognitive and epistemic dispositions}

\footnotetext{
${ }^{1}$ Our selection of traits was based on two priors pilot studies conducted respectively on March $13^{\text {th }}$ and March $16^{\text {th }}$ (see osf.io/497s $2 /$ and osf.io/t93ms/). These pilot studies led us to exclude the following predictors: need for uniqueness, trust in personal experience, scientific literacy, cognitive reflection test, state and trait anxiety. These predictors were excluded because they did not significantly predict participants' intention to comply with health recommendations.
} 
The first set of factors that could drive compliance with health recommendations have to do with individuals' epistemic (knowledge-related) dispositions. Much research in recent years has been devoted to uncovering which psychological traits drive individuals' tendency to endorse conspiracist (Lantian, Muller, Nurra, \& Douglas, 2016) and pseudoscientific beliefs (Majima, 2015) over the official discourse of political and scientific authorities. Research has shown that dispositions to trust one's intuitions for facts, the conviction that truth is politically constructed (Garrett \& Weeks, 2017), and narcissism (Ames, Rose, \& Anderson, 2006) are related to misperception and conspiracist ideation.

Arguably, individuals who favor alternative narratives are likely to disregard governmental organizations' messages, such as those regarding health behaviors during the COVID-19 pandemic. Thus, we hypothesized that (H1) the propensity to hold conspiracist, pseudoscientific, and "political-truth" beliefs, as well as narcissism and trusting one's intuitions, would be related to the rejection of health recommendations to avoid the spread of the coronavirus.

Recent literature on the relation between conspiracist thinking and health behaviors shows mixed results. Some studies suggest that conspiracy mentality is related to health behaviors (Marinthe, Brown, Delouvée, \& Jolley, 2020), while other studies suggest there is no such relation (Imhoff \& Lamberty, 2020). Similarly mixed results are found when looking at conspiracy beliefs about COVID-19 in particular (see Erceg, Ružojčić \& Galić, 2020; Freeman et al., 2020; in contrast to Romer, Jamieson \& Hall, 2020; Alper, Bayrak, Yilmaz, 2020). Finally, some studies have found that traits related to conspiracy mentality, in particular narcissism, are directly linked to preventive behaviors (Nowak et al., 2020). Thus, despite a relatively large amount of research on the topic, the link between epistemic dispositions and health behaviors during the COVID-19 pandemic is still unclear. 


\subsection{Moral values and dispositions}

The second set of factors that could be related to health behaviors during the COVID-19 pandemic have to do with individuals' moral values. Research has shown that the moral domain can be built upon different "foundations" (Graham et al., 2011). For example, some individuals give high importance to avoiding harm to others (Care moral foundation) when making moral judgments and decisions, while others give more importance to respecting individual freedom (Liberty moral foundation, Iyer et al., 2012). In other words, people differ in their conceptions of right and wrong, or the factors that they consider relevant when deciding what the morally right path of action is. Some of these differences could be relevant in the context of health behaviors during the COVID-19 pandemic.

The first relevant moral foundation is the Care foundation. From an individual's perspective, the aim of adopting health behaviors during the COVID-19 pandemic is two-fold: to avoid catching the virus and to avoid spreading it. Arguably, individuals who consider that caring about others is essential for morality might be more likely to act in ways that will protect others from harm (e.g., due to viral infection). Thus, one could expect a greater emphasis on the Care moral foundation will predict higher compliance with official regulations (see Chan, 2020; Harper, Satchell, Fido, \& Latzman, 2020; Qian \& Yahara, 2020). Similarly, the ability to see things from others' points of view or perspective-taking (Davis, 1983) might also motivate health behaviors. ${ }^{2}$ In line with these considerations, we hypothesized that $(\mathrm{H} 2)$

\footnotetext{
${ }^{2}$ Although perspective-taking could be considered a cognitive factor, we include it in this section because, in the context of our argument, it is arguably more relevant to moral (care) concerns than belief-formation processes. Moreover, Davis' perspective-taking subscales is not only about the ability to take the perspective of others, but mostly about the motivation and willingness to take every perspective into account (e.g. "Before criticizing somebody, I try to imagine how I would feel if I were in their place", "I believe that there are two sides to every
} 
individuals who are prone to perspective-taking and give moral weight to caring about others would be more likely to follow health recommendations during the COVID-19 pandemic.

A second relevant moral foundation is Liberty. Indeed, compliance with official health regulations imposes significant restrictions on individual freedom. Health behaviors require individuals to limit the range of actions that they would normally consider and behave only in ways compliant with the guidelines provided by governments and official organizations. Thus, moral convictions about the importance of individual freedom can also be relevant in this context. In line with this hypothesis, Byrd and Bialek (2020) found that the more participants valued liberty over equality, the less likely they were to comply with official regulations. Thus, we hypothesized that (H3) individuals who build their moral convictions on liberty considerations would be less likely to endorse health recommendations.

\subsection{Emotional dispositions}

Several emotional traits are potentially related to compliance with health recommendations during the COVID-19 pandemic. Here, we will consider the role of fear, disgust, empathic concern, and psychological reactance.

Fear and disgust have the function of protecting oneself from dangerous or contaminating situations, respectively (Lazarus, 1991). Fear is typically triggered in situations where we might experience physical harm (e.g., being assaulted by a gunman), while disgust is typically triggered by situations that might threaten our health (e.g., being in contact with

question and try to look at them both.") As such, it is also a measure of how important it is to people to take others' perspectives into account when making a decision. 
rotten food). In turn, both fear and disgust motivate avoidance behaviors. Given that COVID19 suppose a threat to our physical health, individuals' tendency to experience fear and disgust could underlie differences in adopting health behaviors.

However, adopting health behaviors aims to protect both oneself and others (see $§ 1.2$.). Thus, empathic concern (Davis, 1983) could also motivate individuals to adopt health behaviors. ${ }^{3}$ Highly empathic individuals are susceptible to others' emotions and might be motivated to endorse health behaviors to spare others from suffering. Conversely, individuals who are low in empathic concern might not be fully aware of the pain that COVID-19 causes in other people and thus ignore health recommendations.

Despite emotions being an obvious candidate to drive health behaviors, little research has tested the effect of disgust, empathy, and fear in the context of the COVID-19 pandemic. Shook, Sevi, Lee, Oosterhoff, \& Fitzgerald (2020) found that pathogen disgust sensitivity predicted some health behaviors (social distancing, hand washing, cleaning / disinfecting) but not others (avoid touching face, wearing a facemask). Pfattheicher et al. (in press) found that affective empathy is related to social distancing. Finally, most studies regarding fear have focused on the fear of COVID-19 in particular (Ahorsu et al., 2020), although Erceg, Ružojčić, \& Galić (2020) found that COVID-19 related worry mediated the effect of trait anxiety on health behaviors.

\footnotetext{
${ }^{3}$ One might wonder why Perspective taking and Empathic concern are separated into different categories (Moral vs. Emotional dispositions) given that they are highly correlated and sometimes co-activated. The reason is as follows. While the "empathic concern" scale clearly measures a certain kind of emotional reaction (e.g. "I often have tender, concerned feelings for people less fortunate than me", "Sometimes I don't feel very sorry for other people when they are having problems"), the perspective taking scale seems to measure a certain strategy and interest in taking others' perspective into account (e.g. "Before criticizing somebody, I try to imagine how I would feel if I were in their place.", "I believe that there are two sides to every question and try to look at them both."). So, it is clear that we are dealing with two different constructs, even though they are correlated.
} 
In light of these considerations, we hypothesized that (H4) empathic concern, fear, and disgust would drive people's compliance with health recommendations during the COVID-19 pandemic. In particular, empathic concern might motivate individuals to adopt health behaviors to spare others from pain, while fear and disgust might motivate individuals to adopt health behaviors to protect themselves.

Lastly, another affective trait could influence health behaviors and has been so far overlooked in the literature: Psychological reactance (Hong \& Faedda, 1996). Psychological reactance refers to the affective state of arousal that individuals experience when their freedom is threatened, making them act to restore their freedom. Individuals high in psychological reactance might see health recommendations as threats to their freedom and thus be motivated to reject them. Moreover, psychological reactance has already been shown to play a role in health behavior, such as smoking (Miller et al., 2006), alcohol consumption, and risky sexual practices (Miller \& Quick, 2010). However, no study to date has tested whether (H5) psychological reactance prevents adopting health behaviors during the COVID-19 pandemic.

\section{Studies 1a and 1b - United States samples}

In order to elucidate what psychological traits underlie individuals' (lack of) compliance with official recommendations, we conducted two studies in U.S. samples during the early days of the pandemic. The first study was exploratory, and the second one was a preregistered confirmatory replication of the first study. In both studies, we measured participants' reported efforts to comply with health recommendations, their attitudes towards the pandemic, and a series of individual differences. These individual differences and our hypotheses regarding them are: 
(H1) The tendency to hold conspiracist, pseudoscientific, and "truth is political" beliefs, as well as related traits (i.e., narcissism and the tendency to trust one's intuitions), will be related to non-compliance with health recommendations.

(H2) Perspective-taking and beliefs about the moral importance of caring about others will be related to compliance with health recommendations.

(H3) Beliefs about the moral importance of liberty will be related to non-compliance with health recommendations.

(H4) Empathic concern, fear, and disgust will be related to compliance with health recommendations.

(H5) Psychological reactance will be related to non-compliance with health recommendations.

\subsection{Study 1a (exploratory study, conducted on March 20th, 2020)}

The study was conducted on March 20th, 2020. All materials and data can be found on osf.io/kar5z/

\subsubsection{Participants}

Participants were United States residents recruited through Amazon Mechanical Turk and completed the survey for a monetary payment. The aim was to obtain a sample of 250 participants, as it has been suggested this is the sample size at which correlations stabilize 
(Schönbrodt \& Perugini, 2013), but 300 participants were recruited to anticipate potential exclusions. After exclusion based on Moral Foundations Questionnaire's attention checks (see below), 228 participants remained (97 identified as women, 130 as men, and one as non-binary; $\left.M_{\text {age }}=39.47, S D_{\text {age }}=11.26\right)$. Sensitivity analyses using $\mathrm{G}^{*}$ Power showed that we had enough power to detect an effect as small as $\mathrm{f}^{2}=.05$ using multiple linear regression with 17 predictors.

\subsubsection{Procedure}

Participants were redirected to an online questionnaire and asked a series of questions (means and standard deviations for all variables can be found in Table 8).

(i) Past and future efforts to follow official recommendations. Participants were presented with a series of four official recommendations to avoid the spread of the coronavirus: (1) avoiding contact with other people (e.g., not shaking hands), (2) washing hands regularly, (3) coughing in one's elbow or a non-reusable tissue rather than in one's hands, and (4) staying at home as much as possible. Each recommendation was accompanied by illustrations from the World Health Organization (WHO) and the Centers for Disease Control and Prevention (CDC). The order of presentation was counterbalanced. For each recommendation, participants were asked (1) how many efforts they made in the past seven days to follow the recommendation, and (2) how many efforts they were planning to make in the upcoming seven days. Participants respond to these questions on a scale from 1 (“none at all”) to 5 (“a lot"). Measures of past efforts $(\alpha=.79)$ and future efforts $(\alpha=.84)$ showed good internal consistency. Thus, we averaged participants' compliance with all four recommendations in two single measures: Past Efforts and Future Efforts. 
(ii) Attitudes towards the Coronavirus outbreak. Afterward, participants reported their agreement with six statements about their perception of the coronavirus outbreak (e.g., "The COVID-19 is one of the most serious health crises in recent times") on a scale from 1 ("fully disagree") to 7 ("fully agree"). However, in this paper we focus on determinants of behavior rather than perceptions, and thus did not include these data in our analysis.

(iii) Number of confinement breaks. Participants were also asked how many times they left their home in the past seven days for reasons that had nothing to do with (i) purchase of necessity goods (e.g., food), (ii) work (e.g., going to the office), or (iii) health (e.g., seeing a medical doctor).

Participants then completed a series of individual differences inventories, presented in counterbalanced order:

(iv) Belief in conspiracy theories (Lantian, Muller, Nurra, \& Douglas, 2016). Participants rated their agreement with one unique statement ("I think that the official version of the events given by the authorities very often hides the truth").

(v) Beliefs in pseudoscience (Majima, 2015). Participants rated their agreement with nine statements (e.g., "Homoeopathic remedies foster spontaneous healing"; $\alpha=.88$ ).

(vi) Belief that truth is political \& Faith in intuition (Garrett \& Weeks, 2017). Participants rated their agreement with eight statements. The first four items measured participants' beliefs that "truth is political" (e.g., "Facts are dictated by those in power"; $\alpha=$ .87). The last four items constituted a measure of participants' trust in intuition (e.g., "I trust my initial feelings about the facts", $\alpha=.93$ ). 
(vii) Narcissism (Ames, Rose, \& Anderson, 2006). Participants chose, from a series of 16 pairs of statements, the one that best corresponds to them (e.g., "I like to be the center of attention" vs. "I prefer to blend in with the crowd"; $\alpha=.88$ ).

(viii) Psychological reactance (Hong \& Faedda, 1996). Participants rated their agreement with 11 statements (e.g., "Advices and recommendations usually induce me to do just the opposite"; $\alpha=.90)$.

(ix) Dispositional fear (Kramer et al., 2020). Participants rated whether a series of 20 statements faithfully describe them (e.g., "I tend to be unsure of myself in tough situations"; $\alpha$ $=.94)$.

(x) Pathogen disgust (Tybur, Lieberman, \& Griskevicius, 2009). Participants rated how disgusting they found seven situations (e.g., "standing close to a person who has body odors"; $\alpha=.87)$.

(xi) Empathic concern \& Perspective-taking (Davis, 1983). Participants rated their agreement with 14 statements, corresponding to Davis' Interpersonal Reactivity Index's (IRI) Empathic Concern and Perspective-taking subscales. The first seven items measured participants' empathic concern (e.g., "I often have tender, concerned feelings for people less fortunate than me", $\alpha=.92$ ). The last seven items measured participants' tendency to take the perspective of others (e.g., "I try to look at everybody's side of a disagreement before I make a decision"; $\alpha=.89)$.

(xii) Moral Foundations Questionnaire (Iyer et al., 2012). Participants' moral values were measured using the Moral Foundations Questionnaire (MFQ). Each item in the questionnaire is related to a specific moral foundation or theme: Care $(\alpha=.79)$, Fairness $(\alpha=$ 
.74), Loyalty ( $\alpha=.82)$, Authority $(\alpha=.82)$, Purity $(\alpha=.89)$, Government/Economic Liberty ( $\alpha$ $=.75)$, Lifestyle Liberty $(\alpha=.57) ;{ }^{4}$ except from two attention checks (e.g. "It is better to do good than to do bad") which we used to exclude inattentive participants.

(xiii) Demographic questionnaire. At the end of the questionnaire, participants were asked to report their (1) age, (2) gender, (3) native language, (4) nationality, (5) number of children, (6) profession, (7) level of education, (8) parents' level of education (if they were still students), (9) religious orientation, (10) frequency of religious practice, (11) political orientation (on three different scales: Liberal, Conservative, Libertarian), and whether (12) they or (13) one of their close relatives/friends have lungs disease, heart disease, or diabetes.

\subsubsection{Results}

Correlations between all predictors and (i) Past Efforts, (ii) Future Efforts, and (iii) Number of confinement breaks can be found in Table 1.

\begin{tabular}{lllc} 
& Past Efforts & Future Efforts & Confinement breaks \\
\hline Pseudoscience & -0.03 & -0.05 & 0.11 \\
Conspiracy & -0.08 & -0.09 & 0.02 \\
Truth is political & 0.02 & 0.00 & -0.05 \\
Faith in Intuition & 0.06 & 0.03 & 0.04 \\
Narcissism & 0.02 & -0.01 & 0.09
\end{tabular}

\footnotetext{
${ }^{4}$ For discussion regarding the internal consistency of MFQ variables, see Tamul et al. (2020, p. 5-6), but also Graham et al. (2011, p. 370).
} 


$\begin{array}{llll}\text { Perspective-taking } & \mathbf{0 . 2 6 * * *} & \mathbf{0 . 2 7} * * * & 0.02 \\ \text { Care values } & \mathbf{0 . 2 1} * * & \mathbf{0 . 2 3} * * * & \mathbf{- 0 . 1 4 *} \\ \text { Fairness values } & 0.04 & 0.09 & \mathbf{- 0 . 1 4 *} \\ \text { Loyalty values } & 0.03 & 0.03 & 0.07 \\ \text { Authority values } & 0.05 & 0.06 & 0.08 \\ \text { Purity values } & 0.03 & 0.00 & 0.09 \\ \text { Ec. Liberty values } & -0.06 & -0.07 & 0.13 \\ \text { Life Liberty values } & 0.05 & 0.07 & -0.06 \\ \text { Dispositional fear } & -0.04 & 0.02 & -0.07 \\ \text { Pathogen disgust } & \mathbf{0 . 1 7 * *} & \mathbf{0 . 2 0} * * & 0.00 \\ \text { Empathic concern } & \mathbf{0 . 1 7 * *} & \mathbf{0 . 2 1} * * & 0.00 \\ \text { Reactance } & \mathbf{- 0 . 1 7 *} & \mathbf{- 0 . 1 5 *} & -0.05 \\ & & & \end{array}$

Table 1. Correlations between all predictors and (i) Past Efforts, (ii) Future Efforts, and (iii) Number of confinement breaks (Study 1a). For Number of confinement breaks, correlations were computed after excluding outliers (more than 2 S.D.s from the mean): $N=217$.

We conducted two linear multiple regression analyses with either (a) Past Efforts or (b) Future Efforts as dependent variables and Pseudoscience, Conspiracy theories, Truth is political, Faith in intuition for facts, Reactance, Narcissism, Dispositional fear, Pathogen disgust, Empathic concern, Perspective-taking, Care values, Fairness values, Loyalty values, Authority values, Purity values, Economic Liberty Values, and Lifestyle Liberty values as predictors. Collinearity diagnostics showed that multicollinearity was not a concern in either model (Tolerance was $>.20$ for all variables; Menard, 1995). 
Results (summarized in Table 3) showed that participants' care values, $B=.167, S E=$ .084, b.c. $C I[.015, .347], t(207)=2.53, p=.048, s r=.160$, pathogen disgust, $B=.107, S E=$ .049, b.c. $C I[.012, .201], t(208)=2.64, p=.039, s r=.167$, and psychological reactance, $B=-$ $.128, S E=.061$, b.c. $C I[-.243,-.004], t(207)=-2.07, p=.039, s r=-.131$, significantly predicted their efforts to comply with official recommendations in the last seven days. Introducing demographic variables in the model made no difference.

Participants' intentions to comply with official recommendations in the next seven days were significantly predicted by participants' pathogen disgust, $B=.111, S E=.046$, b.c. $C I$ $[.024, .202], t(207)=3.00, p=.018, s r=.189$. Introducing demographic variables in the model didn't change this result. Education was found to be a significant predictor of future compliance $(s r=.130)$

Exploratory analyses showed that participants' number of confinement breaks were significantly predicted by their Economic Liberty values, $B=.535, S E=.173$, b.c. $C I[.194$, $.876], t(212)=2.77, p=.004, s r=.164$. Introducing demographic variables in the model didn't change this result. Liberal political orientation was found to be a significant predictor of number of confinement breaks $(s r=.193)$

\subsection{Study 1 (preregistered confirmatory study, conducted on March 30th, 2020)}

Study 1a was mainly exploratory. In order to confirm our main findings, we conducted a direct replication using a representative sample of the U.S. population. Hypotheses, design, and analysis plan were preregistered (see https://osf.io/d3tf8). 
The study was conducted on March 30th, 2020. All materials and data can be found on osf.io/kdthp/

\subsubsection{Participants}

Participants were recruited through Prolific and completed the survey for a monetary payment. Participants were screened to obtain a representative sample of the United States population. In total, 300 participants completed the survey. After exclusion based on Moral Foundations Questionnaire's attention checks, 273 participants remained. 137 identified as women, 134 as men, and two as non-binary. Mean age was $46.57(S D=15.39$, age-range $=19$ to 80$)$. Sensitivity analyses using $G^{*}$ Power showed that we had enough power to detect an effect as small as $\mathrm{f}^{2}=.04$ using multiple linear regression with 17 predictors.

\subsubsection{Procedure}

The procedure was the same as in Study 1a (see section 2.1.2; means and standard deviations for all variables can be found in Table 8). Demographics included a question about social media use, which could help identify the most appropriate means to communicate with non-compliers.

\subsubsection{Results}

Correlations between all predictors and (i) Past Efforts, (ii) Future Efforts, and (iii) Number of confinement breaks can be found in Table 2 . 


$\begin{array}{ll} & \text { Confinement } \\ \text { Past Efforts } \quad \text { Future Efforts } & \text { breaks }\end{array}$

\begin{tabular}{|c|c|c|c|}
\hline Pseudoscience & .01 & -.02 & -.09 \\
\hline Conspiracy & -.05 & -.12 & -.06 \\
\hline Truth is political & -.07 & -.10 & -.07 \\
\hline Faith in Intuition & .04 & .02 & -.04 \\
\hline Narcissism & -.04 & -.05 & -.02 \\
\hline Perspective-taking & $.26^{* *}$ & $.30^{* *}$ & -.03 \\
\hline Care values & $.31^{* *}$ & $.26^{* *}$ & -.09 \\
\hline Fairness values & $.21^{* *}$ & $.16^{* *}$ & -.01 \\
\hline Loyalty values & .03 & .09 & .07 \\
\hline Authority values & .05 & .06 & .03 \\
\hline Purity values & -.02 & -.01 & -.02 \\
\hline Ec. Liberty values & -.10 & -.10 & -.04 \\
\hline Life Liberty values & .01 & -.01 & .01 \\
\hline Dispositional fear & .00 & -.03 & -.05 \\
\hline Pathogen disgust & $.13^{*}$ & .08 & $-.15^{*}$ \\
\hline Empathic concern & $.27^{* * *}$ & $.28^{* *}$ & -.02 \\
\hline Reactance & $-.20^{* *}$ & $-.23^{* *}$ & .00 \\
\hline
\end{tabular}

Table 2. Correlations between all predictors and (i) Past Efforts, (ii) Future Efforts, and (iii) Number of confinement breaks (Study 1b). For Number of confinement breaks, correlations were computed after excluding outliers (more than 2 SDs from the mean): $N=268$. 
The same linear multiple regression analyses as in Study 1a were conducted. Results are presented in Table 3. Collinearity diagnostics showed that multicollinearity was not a concern in none of the models (Tolerance was >.20 for all variables; Menard, 1995).

Results showed that participants' care values, $B=.152, S E=.071$, b.c. $C I[.024, .295]$, $\mathrm{t}(250)=2.72, p=.032, s r=.156$, and pathogen disgust, $B=.083, S E=.029$, b.c. $C I[.026$, $.137], \mathrm{t}(250)=2.60, p=.006, s r=.149$, significantly predicted their efforts to comply with official recommendations in the last seven days. Introducing demographic variables made no difference.

Participants' intentions to comply with official recommendations in the next seven days were significantly predicted by pathogen disgust, $B=.058, S E=.025$, b.c. $C I[.009, .102]$, $t(250)=2.09, p=.026, s r=.120$. Introducing demographic variables in the model turned the effect of pathogen disgust non-significant $(p=.077)$.

Exploratory analyses showed that participants' number of confinement breaks were significantly predicted by their pathogen disgust sensitivity, $B=-.228, S E=.115$, b.c. $C I[-$ $.467, .003], t(261)=-1.99, p=.046, s r=-.123$. Introducing demographic variables in the model didn't change this result. Gender was found to be a significant predictor of number of confinement breaks $(s r=1.51)$, with women reporting less confinement breaks.

Past efforts $\quad$ Future efforts

Study la Study $1 b \quad$ Study la Study $1 b$


Published in Cognition and Emotion: https://doi.org/10.1080/02699931.2021.1941783

\begin{tabular}{|c|c|c|c|c|c|}
\hline Constant & & $3.75(.43)$ & $3.72(.51)$ & $3.90(.40)$ & $4.12(.47)$ \\
\hline \multirow{2}{*}{ Pseudoscience } & $B(S E)$ & $-.03(.07)$ & $.01(.06)$ & $-.02(.06)$ & $-.01(.05)$ \\
\hline & $s r$ & -.026 & .013 & -.019 & -.008 \\
\hline \multirow{2}{*}{ Conspiracy } & $B(S E)$ & $-.02(.02)$ & $-.01(.01)$ & $-.01(.02)$ & $-.02(.01)$ \\
\hline & $s r$ & -.049 & -.026 & -.038 & -.087 \\
\hline Truth is & $B(S E)$ & $.05(.04)$ & $-.02(.02)$ & $.04(.03)$ & $-.02(.01)$ \\
\hline Political & $s r$ & .097 & -.052 & .079 & -.063 \\
\hline Faith in & $B(S E)$ & $.02(.04)$ & $.03(.03)$ & $-.01(.04)$ & $.03(.03)$ \\
\hline Intuition & $s r$ & .031 & .055 & -.013 & .081 \\
\hline \multirow{2}{*}{ Narcissism } & $B(S E)$ & $.25(.26)$ & $-.02(.01)$ & $.24(.22)$ & $-.01(.01)$ \\
\hline & $s r$ & .068 & -.068 & .071 & -.059 \\
\hline Perspective- & $B(S E)$ & $.08(.05)$ & $.06(.05)$ & $.07(.05)$ & $.08(.04)$ \\
\hline taking & $s r$ & .112 & .094 & .105 & .141 \\
\hline \multirow{2}{*}{ Care values } & $B(S E)$ & $.17(.08)$ & $.15(.07)$ & $.13(.08)$ & $.09(.06)$ \\
\hline & $s r$ & $.160 *$ & $.156^{*}$ & .139 & .109 \\
\hline Fairness & $B(S E)$ & $-.09(.08)$ & $.02(.06)$ & $-.05(.08)$ & $-.01(.05)$ \\
\hline values & $s r$ & -.081 & .022 & -.051 & -.007 \\
\hline Ingroup & $B(S E)$ & $-.06(.08)$ & $-.03(.05)$ & $-.04(.07)$ & $.02(.05)$ \\
\hline values & $s r$ & -.068 & -.033 & -.046 & .034 \\
\hline Authority & $B(S E)$ & $.05(.07)$ & $.07(.08)$ & $.07(.06)$ & $.04(.08)$ \\
\hline values & $s r$ & .040 & .064 & .069 & .039 \\
\hline \multirow{3}{*}{ Purity values } & $B(S E)$ & $-.02(.05)$ & $-.07(.05)$ & $-.05(.04)$ & $-.05(.06)$ \\
\hline & $s r$ & -.024 & -.109 & -.071 & -.089 \\
\hline & $B(S E)$ & $-.11(.08)$ & $-.06(.05)$ & $-.08(.07)$ & $-.06(.04)$ \\
\hline
\end{tabular}




\begin{tabular}{|c|c|c|c|c|c|}
\hline $\begin{array}{l}\text { Ec. Liberty } \\
\text { values }\end{array}$ & $s r$ & -.085 & -.076 & -.070 & -.084 \\
\hline Life Liberty & $B(S E)$ & $.02(.06)$ & $-.02(.04)$ & $.00(.05)$ & $-.02(.03)$ \\
\hline values & $s r$ & -.025 & -.029 & .002 & -.030 \\
\hline Pathogen & $B(S E)$ & $.11(.05)$ & $.08(.03)$ & $.11(.05)$ & $.06(.02)$ \\
\hline disgust & $s r$ & $.167 *$ & $.149 *$ & $.190 *$ & $.120 *$ \\
\hline Dispositional & $B(S E)$ & $.06(.10)$ & $-.02(.05)$ & $.02(.09)$ & $-.01(.05)$ \\
\hline fear & $s r$ & .051 & -.017 & .015 & -.015 \\
\hline Empathic & $B(S E)$ & $.02(.06)$ & $.02(.04)$ & $.03(.05)$ & $.02(.04)$ \\
\hline Concern & $s r$ & .019 & .029 & .047 & .029 \\
\hline \multirow{2}{*}{ Reactance } & $B(S E)$ & $-.13(.06)$ & $-.06(.06)$ & $-.10(.06)$ & $-.05(.05)$ \\
\hline & $s r$ & $-.131 *$ & -.062 & -.109 & -.064 \\
\hline \multicolumn{6}{|l|}{$R^{2} / R^{2}$} \\
\hline adjusted & & $.17 / .10$ & $.18 / .13$ & $.17 / .10$ & $.18 / .12$ \\
\hline
\end{tabular}

Table 3. Regression coefficients (bootstrapped standard errors) and semi-partial correlations for predictors of past and future efforts to follow official recommendations in Studies 1a and 1b. * indicates $p<.05, * *$ indicates $p<.01$

\subsection{Discussion}

In our first two studies, we investigated possible cognitive and affective factors driving compliance with official recommendations regarding the COVID-19 pandemic. Results suggest that spread-prevention behaviors are not driven by individual differences in conspiracist and pseudoscientific beliefs (H1), liberty moral values (H3), or dispositional fear 
(H4). Instead, people's past and future compliance were correlated with care values and perspective-taking (H2), disgust towards pathogens and empathic concern (H4), and psychological reactance (H5). Regression analyses show that, once controlled for other predictors, pathogen disgust, care values, and (to a lesser extent) psychological reactance were the most relevant predictors.

Results regarding participants' care values consistently reached significance with regards to past efforts to follow official recommendations, but not with regards to future efforts. While this could be simply be due to random variations in data, perhaps these results are telling us something about participants' reports of past vs. future efforts. One possible explanation is that participants tend to report higher intentions to follow recommendations in the future. If participants' high in care values already reported high efforts in the past, there might be a ceiling effect with regards to their reported future efforts.

Previous studies have found that conspiracist and pseudoscientific beliefs are related to compliance with distancing (but not hygiene) behaviors during the COVID-19 pandemic (see van Mulukom et al. 2020). Thus, it might be that we failed to support $\mathrm{H} 1$ because our analyses didn't distinguish between these two types of preventive behaviors. In order to address this worry, we computed Past and Future Distancing Efforts variables as participants' average efforts to avoid social contact and confine themselves (recommendations 1 and 4, see §2.1.2.), and rerun our multiple linear regression analyses using these new measures as the dependent variables. Neither Conspiracy, Pseudoscience, Truth is Political, Faith in Intuition, or Narcissism variables showed a significant effect in participants' past or future distancing efforts (all $p s>.23)$. 
However, none of our predictors consistently correlated with our more indirect measure of compliance: number of confinement breaks. This might be because this measure was not an accurate measure of compliance. Research suggests that desirability bias is not a concern in self-reported compliance with health recommendations during the COVID-19 pandemic (Jensen, 2020). However, a vast array of factors might influence the number of confinement breaks, and some forms of breaking the confinement (e.g., taking a walk in an isolated area) are compatible with health recommendations. Thus, we wanted to find a measure of compliance that might be less subjective than participants' self-reported efforts to comply with official recommendations. In order to do this, we conducted two follow-up studies on French samples in which we asked participants about a variety of behaviors that might be perceived as going against official recommendations.

\section{Studies $2 a$ and $2 b-$ French samples}

\subsection{Study 2 a (conducted on August 2nd and September 5th, 2020)}

In Study 2a, our goal was (i) to see if the results of studies $1 \mathrm{a}$ and $1 \mathrm{~b}$ could be generalized to another country (France), and (ii) whether pathogen disgust, care values, and psychological reactance (the predictors identified in studies $1 \mathrm{a}$ and $1 \mathrm{~b}$ ) would encourage people not to engage in behavior likely to contribute to the spread of the COVID-19 pandemic. The study was preregistered on OSF at osf.io/esnvb. All materials and data can be found at osf.io/3e4g8/

The three target behaviors were behaviors that were highly debated or criticized in French media at the time: going to vote in the $1^{\text {st }}$ turn of the French municipal election (March 
15th, just before lockdown), going to vote in the $2^{\text {nd }}$ turn of the French municipal election (June 28th, after lockdown), going to the 2020 Fête de la Musique (a national outdoor event in which musicians are allowed to play music in public spaces throughout France, June 21st). Our hypotheses were:

(H2) Perspective-taking and beliefs about the moral importance of caring about others will predict compliance with health recommendations.

(H4*) Disgust will predict compliance with health recommendations.

(H5) Psychological reactance will predict non-compliance with health recommendations.

The study was conducted in two sessions on August 2nd and September 5th, 2020. All materials and data can be found on osf.io/3e $4 \mathrm{~g} 8 /$

\subsubsection{Participants}

Participants were recruited through Crowdpanel; a website specialized in the recruitment of French participants, and completed the survey for a monetary payment. In the first recruitment session, a total of 304 participants completed our study. Out of these 304 participants, 91 failed at least one attention check, leaving us with 213 participants. Because this fell way below our target sample size, a second recruitment session added 97 extra participants. After exclusion, we were left with 289 participants $(M=42.67, S D=13.04 ; 164$ women, 124 men, 1 other $)$. Sensitivity analyses using $G^{*}$ Power showed that we had enough power to detect an effect as 
small as $\mathrm{f}^{2}=.04$ using multiple linear regression with eight predictors, and an effect as small as $\mathrm{z}=-1.96$ using logistic regression.

\subsubsection{Procedure}

Participants were redirected to an online questionnaire in which they were asked the following questions (means and standard deviations for all variables can be found in Table 8):

(i) Past compliance. Compliance with official regulations during the first French lockdown (past compliance). Participants were presented with five official regulations (stay at home as much as possible, coughing in one's elbow, avoiding touching one's face, keeping social distances, washing one's hands) and asked to indicate to which extent they respected them during lockdown (from $0=$ not at all, to $5=$ systematically, without exception). We averaged participants' compliance with all five regulations in a single Past Efforts measure ( $\alpha$ $=.76)$.

(ii) Future compliance. Intentions to comply with official regulations in the next two weeks (future compliance). Participants were presented with six official regulations (wearing a mask in public transports and places, keeping a one-meter social distance, avoiding touching one's face, avoiding kissing or shaking hands, washing one's hands, avoiding big family reunions) and asked to indicate to which extent they intended to respect them during the next two weeks (from $0=$ not at all, to $5=$ systematically, without exception). We averaged participants' compliance with all five regulations in a single Future Efforts measure $(\alpha=.80)$.

(iii) Precautionary behavior, I. Participants were asked whether they went to vote on the $1^{\text {st }}$ turn of French municipal election (YES/NO) and, if they answered 'NO', whether they 
would have gone in the absence of COVID-19 (YES/NO/I don't know). Participants who declared not having voted, but that they would have voted in absence of COVID-19 were counted as exhibiting "precautionary behavior". Participants who declared that they would not have voted even in the absence of COVID-19 were excluded from the analysis.

(iv) Precautionary behavior, II. Participants were asked whether they went to vote on the $2^{\text {nd }}$ turn of the French municipal election (YES/NO/There was no second turn in my town) and, if they answered 'NO', whether they would have gone in the absence of COVID-19 (YES/NO/I don't know). Participants who declared not having voted, but that they would have voted in absence of COVID-19 were counted as exhibiting "precautionary behavior". Participants who declared that they would not have voted, even in the absence of COVID-19, were excluded from the analysis.

(v) Precautionary behavior, III. Participants were asked whether they went to the 2020 Fête de la Musique (YES/NO) and, if they answered 'NO', whether they went to the 2019 Fête de la Musique (YES/NO/I don't remember). Participants who answer NO to the first question and YES to the second question were counted as exhibiting "precautionary behavior". Participants who answered NO or "I don't remember" to the second question were excluded from the analysis.

(vi) Predictors. Pathogen disgust, psychological reactance, and perspective-taking. Participants were then presented with a French version of the Moral Foundations Questionnaire,5 Pathogen Disgust, Psychological Reactance, and Perspective-Taking scales used in Studies 1a and 1b.

\footnotetext{
${ }^{5}$ In contrast to Studies 1a and 1b, we did not include the two Liberty foundations in our measures of moral values. There were two reasons for this decision: First, existing French version of the Moral Foundations Questionnaire
} 
(viii) Demographic information. At the end of the questionnaire, participants were asked for several demographic information (age, gender, language, residence, study level, political orientation, whether they got COVID-19).

3.1.3. Predictors of compliance with official regulations.

Correlations between all predictors and (i) Past compliance, (ii) Future compliance (iii) Precautionary behavior I, and (iv) Precautionary behavior II can be found in Table 4.

\begin{tabular}{lllll} 
& \multicolumn{2}{l}{ Compliance } & \multicolumn{2}{l}{ Voting } \\
\cline { 2 - 5 } & Past & Future & $1^{\text {st }}$ Round & $2^{\text {nd }}$ Round \\
\hline Perspective-taking & 0.10 & $\mathbf{0 . 1 3} *$ & 0.01 & 0.00 \\
Care values & $\mathbf{0 . 2 3} * * *$ & $\mathbf{0 . 2 1} * * *$ & 0.08 & 0.05 \\
Fairness values & $\mathbf{0 . 1 6 * *}$ & 0.10 & -0.03 & -0.08 \\
Loyalty values & $\mathbf{0 . 1 3 *}$ & 0.11 & 0.03 & 0.01 \\
Authority values & $\mathbf{0 . 1 6 * *}$ & $\mathbf{0 . 1 8 * *}$ & -0.08 & 0.01 \\
Purity values & $\mathbf{0 . 1 6 * *}$ & $\mathbf{0 . 2 0} * * *$ & 0.08 & 0.06 \\
Pathogen disgust & $\mathbf{0 . 1 4 *}$ & $\mathbf{0 . 1 9 *}$ & $\mathbf{0 . 1 6 *}$ & $\mathbf{0 . 2 3} *$ \\
Psychological reactance & $\mathbf{- 0 . 1 5 *}$ & $\mathbf{- 0 . 2 1 *}$ & -0.13 & -0.17 \\
& & & &
\end{tabular}

does not include the two Liberty foundations. Second, the internal coherence of the Liberty foundations in Studies $1 \mathrm{a}$ and $1 \mathrm{~b}$ was very low. 
Table 4. Correlations between all predictors and (i) Past compliance, (ii) Future compliance (iii) Precautionary behavior I, and (iv) Precautionary behavior II (Study 2a).

To identify the predictors of compliance with official regulations, we ran multiple regression analyses with past and future compliance as a dependent variable and (i) pathogen disgust, (ii) psychological reactance, (iii) perspective-taking, and (iv) all five moral foundations as predictors. The results are presented in Table 2 .

No variable significantly predicted past compliance. Future compliance was significantly predicted by both Pathogen Disgust, $B=.099, S E=.036$, b.c. $C I$ [.028, .164], $\mathrm{t}(288)=2.33, p=.007, s r=.129$, and Psychological Reactance, $B=-.226, S E=.103$, b.c. $C I$ $[-.437,-.015], \mathrm{t}(288)=-3.13, p=.033, s r=-.171$. After introducing demographic variables into the model, these effects remained significant. Furthermore, Age and Gender were significant predictors of both Past $\left(s r_{\mathrm{Age}}=.134, s r_{\mathrm{Gender}}=.204\right)$ and Future compliance $\left(s r_{\mathrm{Age}}=\right.$ $.207, s r_{\text {Gender }}=.254$ ), with women reporting higher intentions to comply.

\subsubsection{Predictors of decisions not to vote.}

We then investigated predictors of people's decision not to vote (a precautionary behavior) on the (first and second turn of the) French municipal elections. The analyses only included (i) participants who went (will go) to vote and (ii) participants who did not (won't) go voting but said that they would have gone to vote in the absence of COVID-19. Participants who answered (i) that they would not have gone voting anyway or (ii) that there was no second turn in their town were excluded. We were left with 188 participants for decisions not to vote on the first 
turn and 95 participants for decisions not to vote on the second turn. We then ran logistic regressions with the decision to vote/not to vote as a dependent variable and (i) pathogen disgust, (ii) psychological reactance, (iii) perspective-taking, and (iv) all five moral foundations as predictors. The results are presented in Table 5 .

Concerning the first round of the elections, 122 participants out of $188(65 \%)$ said they went to vote. Pathogen Disgust positively predicted the decision not to vote, $B=.407, S E=$ .190, b.c. $C I[.036, .872], p=.016$, while Psychological Reactance $(B=-.620, S E=.305, b . c$. $C I[-1.201,-.226], p=.028)$ and the Authority foundation predicted the decision to vote, $B=-$ $.878, S E=.321$, b.c. $C I[-1.418,-.392], p=.002$. Introducing demographic variables into the model made no difference.

Concerning the second round, 47 participants out of 95 (49\%) said they went to vote. Pathogen Disgust positively predicted the decision not to vote, $B=.732, S E=.327$, b.c. $C I$ $[.051,2.028], p=.008$, while Psychological Reactance predicted the decision to vote, $B=-$ $1.029, S E=.494$, b.c. $C I[-1.853,-.545], p=.011$. Introducing demographic variables into the model made no difference.

3.1.5. Predictors of decisions not to go to the Fête de la Musique.

On a total of 289 participants, only three declared having been to the 2020 Fête de la Musique. Thus, we dropped this analysis. 
Published in Cognition and Emotion: https://doi.org/10.1080/02699931.2021.1941783

\begin{tabular}{|c|c|c|c|c|c|}
\hline & & Past & Future & $1^{\text {st }}$ round & $2^{\text {nd }}$ round \\
\hline \multirow{2}{*}{ Constant } & & $2.85 * *$ & $3.25 * *$ & .75 & 2.55 \\
\hline & & $(.54)$ & $(.53)$ & $(1.90)$ & $(2.90)$ \\
\hline Perspective & $B(S E)$ & $.00(.01)$ & $.00(.01)$ & $-.02(.03)$ & $-.02(.06)$ \\
\hline -taking & $s r$ & .011 & .027 & & \\
\hline Care & $B(S E)$ & $.15(.11)$ & $.15(.11)$ & $.29(.31)$ & $.13(.48)$ \\
\hline values & $s r$ & .102 & .106 & & \\
\hline Fairness & $B(S E)$ & $.15(.09)$ & $.10(.08)$ & $-.16(.33)$ & $-.07(.58)$ \\
\hline values & $s r$ & .097 & .070 & & \\
\hline Ingroup & $B(S E)$ & $-.02(.08)$ & $-.06(.07)$ & $.33(.30)$ & $.01(.46)$ \\
\hline values & $s r$ & -.013 & -.046 & & \\
\hline Authority & $B(S E)$ & $.05(.07)$ & $.06(.07)$ & $\begin{array}{l}-.88 * \\
(.32)\end{array}$ & $-.75(.53)$ \\
\hline values & $s r$ & .035 & .047 & & \\
\hline Purity & $B(S E)$ & $.05(.06)$ & $.08(.05)$ & $.22(.26)$ & $.03(.37)$ \\
\hline values & $s r$ & .046 & .084 & & \\
\hline \multirow{2}{*}{$\begin{array}{l}\text { Pathogen } \\
\text { disgust }\end{array}$} & $B(S E)$ & $.07(.04)$ & $.10(.04)$ & $\begin{array}{l}.41 * \\
(.19)\end{array}$ & $\begin{array}{l}.73 * \\
(.33)\end{array}$ \\
\hline & $s r$ & .086 & $.129 *$ & & \\
\hline \multirow[t]{2}{*}{ Reactance } & $B(S E)$ & $-.19(.10)$ & $-.23(.10)$ & $\begin{array}{l}-.62 * \\
(.30)\end{array}$ & $\begin{array}{l}-\mathbf{1 . 0 3} * \\
(.49)\end{array}$ \\
\hline & $s r$ & -.133 & $-.171 *$ & & \\
\hline $\begin{array}{l}\mathrm{R}^{2} \\
\text { (Nagelkerk }\end{array}$ & & $.10 / .07$ & $.13 / .11$ & .13 & .18 \\
\hline
\end{tabular}


e) /

\section{$\mathrm{R}^{2}$ adjusted}

Table 5. Regression coefficients (and bootstrapped standard errors) for predictors of past and future efforts to follow official recommendations, as well as decisions to vote in the first and second rounds of the elections (Study $2 \mathrm{a}) . *$ indicates $p<.05, * *$ indicates $p<.01$.

\subsection{Study 2 b (conducted on November 1st, 2020)}

In Study 2a, we found that pathogen disgust and psychological reactance predicted compliance with official regulations and decisions (not) to go voting due to the COVID-19 pandemic in a French sample. In Study $2 b$, we sought to replicate those results and extend them by investigating to which extent pathogen disgust and psychological reactance predicted whether people engaged in an array of risky behaviors (going to the cinema, going to a restaurant, going to parties). Due to budgetary constraints, we were not able to include all predictors (and thus left moral values and perspective-taking aside. The study was preregistered on OSF at osf.io/vuz94.

The study was conducted in two sessions on November 1st, 2020. All materials and data can be found on osf.io/ac9vj/

\subsubsection{Participants}

Participants were recruited through Crowdpanel; a website specialized in the recruitment of French participants, and completed the survey for a monetary payment. A total of 297 
participants completed our study. Out of these 297 participants, 10 failed our attention check, leaving us with 287 participants $(M=40.80, S D=13.31 ; 144$ women, 143 men $)$. Sensitivity analyses using $\mathrm{G}^{*}$ Power showed that we had enough power to detect an effect as small as $\mathrm{f}^{2}=$ .04 using multiple linear regression with three predictors.

\subsubsection{Procedure}

Participants were redirected to an online questionnaire in which they were asked the following questions (means and standard deviations for all variables can be found in Table 8):

(i) Past compliance. Compliance with official regulations during the past two weeks (those who immediately preceded the second French lockdown). Participants were presented with six official regulations (staying at home as much as possible, coughing in one's elbow, avoiding touching one's face, keeping social distances, washing one's hands, avoiding big meetings with family and friends) and asked to indicate to which extent they respected them during the past two weeks (from $0=$ not at all, to $5=$ systematically, without exception). We averaged participants' answers to the six items $(\alpha=.75)$.

(ii) Future compliance. Intentions to comply with official regulations in the next two weeks (the two first weeks of the second French lockdown). Participants were presented with the same six official regulations and asked to indicate to which extent they intended to respect them during the next two weeks (from $0=$ not at all, to $5=$ systematically, without exception). We averaged participants' answers to the six items $(\alpha=.81)$.

(iii) Precautionary behavior, I \& II. These measures were the same as in Study 2a. 
(iv) Risky behavior: Participants were asked whether, in the past two weeks, they (a) went to the cinema or theatre for non-professional reasons, (b) went to the restaurant for nonprofessional reasons, or (c) went to a party between colleagues, friends or members of the same family. Answers were binary (YES/NO), and participants were attributed a 'risky behavior score' based on the number of 'YES' answers they provided $(\alpha=.38)$.

(v) Pathogen disgust and psychological reactance: Participants were then presented with a French version of the Pathogen Disgust $(\alpha=.75)$ and Psychological Reactance scales $(\alpha=.80)$.

(ix) Demographic information: At the end of the questionnaire, participants were asked for several demographic information (age, gender, language, residence, study level, political orientation, whether they got COVID-19).

(x) Other measures: We took advantage of this study to try and replicate from another study (Fuhrer \& Cova, 2020). To this aim, the Faith in Intuition scale used in Studies 1a and $1 \mathrm{~b}$ was reintroduced. We also asked participants a series of questions about their perception of hydroxychloroquine-based treatments against COVID-19 and their French promoter. We discuss these results elsewhere (see Fuhrer \& Cova, 2020).

3.2.3. Predictors of compliance with official regulations.

Correlations between all predictors (pathogen disgust and psychological reactance,) and (i) Past compliance, (ii) Future compliance (iii) Precautionary behavior I, (iv) Precautionary behavior II and (v) Risky behaviors can be found in Table 6 . 


\begin{tabular}{|c|c|c|c|c|c|}
\hline & Past & Future & Precaution I & Precaution II & Risky \\
\hline Pathogen & 0.10 & 0.12 & 0.13 & 0.06 & -0.06 \\
\hline \multicolumn{6}{|l|}{ disgust } \\
\hline Psychological & $-0.15 *$ & $-0.16 * *$ & -0.06 & -0.01 & 0.06 \\
\hline
\end{tabular}

Table 6. Correlations between all predictors (pathogen disgust and psychological reactance) and (i) Past compliance, (ii) Future compliance (iii) Precautionary behavior I, (iv) Precautionary behavior II and (v) Risky behaviors (Study 2b).

To identify the predictors of compliance with official regulations, we ran two multiple regression analyses with Past and Future Compliance as a dependent variable and (i) pathogen disgust and (ii) psychological reactance, as predictors. The results are presented in Table 7.

Past compliance was significantly predicted by Pathogen Disgust $(B=.118, S E=.059$, b.c. $C I[.010, .232], t=2.19, p=.043, s r=.128)$ and Psychological Reactance $(B=-.245, S E$ $=.092$, b.c. $C I[-.437,-.054], t=-2.92, p=.005, s r=-.170)$. Future compliance was significantly predicted by Pathogen Disgust $(B=.122, S E=.048$, b.c. $C I[.024, .226], t=2.60$, $p=.014, s r=.151)$ and Psychological Reactance $(B=-.237, S E=.076$, b.c. $C I[-.390,-.077]$, $t=-3.25, p=.002, s r=-.188)$.

Introducing demographic variables into the model did not change our conclusions. Age turned out to be a significant positive predictor of Past compliance $(s r=0.212)$ and Future 
compliance $(s r=0.164)$. Gender was a significant predictor of Past compliance $(s r=0.139)$ and Future compliance $(s r=0.205)$, with women reporting higher intentions to comply.

\subsubsection{Predictors of precautionary behavior (decisions not to vote)}

We then investigated predictors of people's decision not to vote (a precautionary behavior) on the (first and second turn of the) French municipal elections. After exclusions (see §3.1.4.) were left with 194 participants for decisions not to vote on the first turn and 116 participants for decisions not to vote on the second turn. We then ran logistic regressions with the decision to vote/not to vote as a dependent variable and (i) pathogen disgust, (ii) psychological reactance, and (iii) faith in intuition as predictors. The results are presented in Table 5.

Concerning the first round of the elections, 125 participants out of 194 (64\%) said they went to vote. Only pathogen disgust significantly predicted precautionary behavior $(B=.317$, $S E=.171$, b.c. $C I[.024, .177], s r=0.137, p=.049)$.

Concerning the second round, 62 participants out of $116(53 \%)$ said they went to vote. None of our predictors significantly predicted precautionary behavior.

Entering demographic information into the model did not change our results.

\subsubsection{Predictors of risky behaviors}

The average risky behavior score was $0.74(S D=0.82)$. We ran a multiple regression analysis with risky behaviors as a dependent variable and (i) pathogen disgust, (ii) psychological 
reactance, and (iii) faith in intuition as predictors. There was no significant predictor of risky behaviors.

However, internal coherence for our measure of risky behavior was weak $(\alpha=.38)$, suggesting that our three examples of risky behaviors might be influenced by very different factors. We thus performed three separate logistic regression, one by behavior, with (i) pathogen disgust, (ii) psychological reactance, and (iii) faith in intuition as predictors. The only significant result was that psychological reactance significantly predicted to which extent French participants went to the restaurant $(B=.112, S E=.043$, b.c. $C I[.031, .193], r=0.143)$.

\begin{tabular}{|c|c|c|c|c|c|}
\hline & & Efforts & & Voting & \\
\hline & & Past & Future & $1^{\text {st }}$ round & $\begin{array}{l}2^{\text {nd }} \\
\text { round }\end{array}$ \\
\hline Constant & & $3.40(.36)$ & $3.98(.31)$ & $\begin{array}{l}-1.51 \\
(1.02)\end{array}$ & $\begin{array}{l}-1.22 \\
(1.26)\end{array}$ \\
\hline \multirow{2}{*}{$\begin{array}{l}\text { Pathogen } \\
\text { disgust }\end{array}$} & $B(S E)$ & $.12(.06)$ & $.12(.05)$ & $.31(.17)$ & $.13(.22)$ \\
\hline & $s r$ & $.128 *$ & $.151 *$ & $.137^{*}$ & .059 \\
\hline \multirow[t]{2}{*}{ Reactance } & $B(S E)$ & $.24(.08)$ & $.24(.08)$ & $-.41(.27)$ & $-.24(.34)$ \\
\hline & $s r$ & $-.170 *$ & $-.188 *$ & -.114 & -.070 \\
\hline $\begin{array}{l}\mathrm{R}^{2} \\
\text { (Nagelkerke) / } \\
\mathrm{R}^{2} \text { adjusted }\end{array}$ & & $.060 / .050$ & $.075 / .065$ & .041 & .024 \\
\hline
\end{tabular}

Table 7. Regression coefficients (and bootstrapped standard errors) for predictors of past and future efforts to follow official recommendations, as well as decisions to vote in the first and second rounds of the elections. * indicates $p<.05, * *$ indicates $p<.01$. 


\subsection{Discussion}

In Studies $2 \mathrm{a}$ and $2 \mathrm{~b}$, we were able to replicate the effect of trait pathogen disgust and psychological reactance on compliance with official recommendations. However, in Study 2a, these effects were only significant for future compliance and not for past compliance. This difference might be because Study 2a was conducted at a moment when the circulation of the SARS-Cov-2 was low (end of summer 2020) but when people were already discussing the possibility of a second wave. Thus, at the moment the survey was conducted, there was less reason to follow preventive behavior based on pathogen disgust (because the virus was perceived as less present) or on psychological reactance (because rules and constraints tended to be less severe), but there were reasons to think these reasons would be present in the weeks to come.

Regarding behavior, in Study 2a both traits significantly predicted decisions to go vote in the municipal elections, while in Study $2 b$ only pathogen disgust significantly predicted decisions to go voting, and only regarding the first round of the elections. Given that measures in both studies bore on the same traits and the very same behavior, we can only attribute this variation to sampling error. We thus should stay cautious when discussing the role of psychological reactance in decisions to go voting.

\begin{tabular}{lcccc} 
& Study $1 a$ & Study $1 b$ & Study $2 a$ & Study $2 b$ \\
\hline Past Efforts & $4.54(0.67)$ & $4.67(0.53)$ & $3.90(0.81)$ & $3.57(0.89)$ \\
Future Efforts & $4.70(0.62)$ & $4.76(0.46)$ & $4.17(0.71)$ & $4.17(0.78)$ \\
Confinement breaks & $0.97(1.46)$ & $1.42(4.20)$ & - & -
\end{tabular}




\begin{tabular}{|c|c|c|c|c|}
\hline Pseudoscience & $2.16(0.81)$ & $2.14(0.66)$ & - & - \\
\hline Conspiracy & $4.75(2.50)$ & $5.27(2.27)$ & - & - \\
\hline Truth is political & $3.26(1.58)$ & $3.31(1.42)$ & - & - \\
\hline Faith in Intuition & $4.24(1.59)$ & $4.49(1.29)$ & - & - \\
\hline Narcissism & $3.04(3.69)$ & $2.63(2.66)$ & - & - \\
\hline Perspective-taking & $5.31(1.23)$ & $5.05(1.10)$ & $4.76(0.86)$ & - \\
\hline Care values & $3.70(0.93)$ & $3.78(0.75)$ & $3.76(0.69)$ & - \\
\hline Fairness values & $3.70(0.85)$ & $3.62(0.73)$ & $3.72(0.63)$ & - \\
\hline Loyalty values & $2.26(1.09)$ & $2.23(0.97)$ & $2.90(0.77)$ & - \\
\hline Authority values & $2.56(1.10)$ & $2.73(0.90)$ & $3.00(0.81)$ & - \\
\hline Purity values & $2.12(1.45)$ & $2.29(1.23)$ & $2.25(0.94)$ & - \\
\hline Ec. Liberty values & $3.00(0.96)$ & $2.92(0.83)$ & - & - \\
\hline Life Liberty values & $3.49(0.93)$ & $3.38(0.94)$ & - & - \\
\hline Dispositional fear & $-2.37(0.67)$ & $1.65(.55)$ & - & - \\
\hline Pathogen disgust & $3.59(1.27)$ & $4.00(1.12)$ & $3.94(1.04)$ & $4.17(0.98)$ \\
\hline Empathic concern & $5.33(1.36)$ & $5.42(1.14)$ & - & - \\
\hline Reactance & $2.52(0.86)$ & $2.60(0.70)$ & $3.02(0.65)$ & $3.09(0.63)$ \\
\hline $\mathrm{N}$ & 228 & 273 & 289 & 287 \\
\hline
\end{tabular}

Table 8. Mean and S.D.s for all main variables across four studies.

\section{General discussion}

In a series of studies, we used different measures and populations to test whether compliance with official recommendations in the context of the COVID-19 pandemic could be predicted 
by the following individual differences: (H1) the tendency to hold conspiracist, pseudoscientific, and "truth is political" beliefs, as well as related traits (i.e., narcissism and the tendency to trust one's intuitions), (H2) perspective-taking and beliefs about the moral importance of caring about others, (H3) beliefs about the moral importance of liberty, (H4) emotional dispositions such as empathic concern, fear, and disgust, and (H5) psychological reactance.

To get a better grasp of the overall results of our research, we conducted a mini-metaanalysis of our Pearson correlation coefficients and semi-partial correlation coefficients (extracted from our regression analyses) for all four studies are presented in Table 9 and for the four variables appearing in our initial hypotheses that appeared in at least three different studies (pathogen disgust, psychological reactance, care values, perspective-taking). Results for Pearson correlations suggest that pathogen disgust, psychological reactance, care values, and perspective-taking significantly all correlate with past and future compliance with recommendations. Moreover, Care values and perspective-taking are the predictors for which correlations are higher.

$\begin{array}{llc}\text { Pathogen } & \text { Psychological Care values } & \text { Perspective- } \\ \text { Disgust } & \text { Reactance } & \text { taking }\end{array}$

(a) Past efforts / compliance

\begin{tabular}{|c|c|c|c|c|c|}
\hline \multirow[t]{2}{*}{ Study 1a } & $r$ & $.17[.04, .29]$ & $-.17[-.29,-.04]$ & $.21[.08, .33]$ & $.26[.13, .38]$ \\
\hline & $s r$ & $.17[.04, .29]$ & $-.13[-.26, .00]$ & $.16[.03, .28]$ & $.11[-.02, .24]$ \\
\hline Study 1b & $r$ & $.13[.01, .24]$ & $-.20[-.31,-.08]$ & $.31[.20, .41]$ & $.26[.14, .36]$ \\
\hline
\end{tabular}


Published in Cognition and Emotion: https://doi.org/10.1080/02699931.2021.1941783

\begin{tabular}{|c|c|c|c|c|c|}
\hline & $s r$ & $.15[.03, .26]$ & $-.06[-.18, .06]$ & $.16[.04, .27]$ & $.09[-.03, .21]$ \\
\hline \multirow[t]{2}{*}{ Study $2 \mathrm{a}$} & $r$ & $.14[.03, .25]$ & $-.15[-.26,-.04]$ & $.10[.12, .34]$ & $.10[-.02, .21]$ \\
\hline & $s r$ & $.09[-.03, .20]$ & $-.13[-.24,-.02]$ & $.10[-.01, .21]$ & $.01[-.10, .13]$ \\
\hline \multirow[t]{2}{*}{ Study $2 b$} & $r$ & $.10[-.02, .21]$ & $-.15[-.26,-.03]$ & - & - \\
\hline & $s r$ & $.13[.01, .24]$ & $-.17[-.28,-.06]$ & & \\
\hline Meta-analytic & & $.13[.07, .19]$ & $-.17[-.22,-.11]$ & $.25[.19, .32]$ & $.20[.10, .31]$ \\
\hline estimate for $\mathrm{r}$ & & $\mathrm{Z}=4.34, \mathrm{p}<.001$ & $\mathrm{Z}=-5.49, \mathrm{p}<.001$ & $\mathrm{Z}=7.22, \mathrm{p}<.001$ & $\mathrm{Z}=3.71, \mathrm{p}<.001$ \\
\hline Meta-analytic & & $.13[.07, .19]$ & $-.12[-.18,-.07]$ & $.14[.07, .21]$ & $.07[.00, .14]$ \\
\hline estimate for $\mathrm{sr}$ & & $\mathrm{Z}=4.28, \mathrm{p}<.001$ & $Z=-4.09, p<.001$ & $\mathrm{Z}=3.87, \mathrm{p}<.001$ & $\mathrm{Z}=1.93, \mathrm{p}=.053$ \\
\hline
\end{tabular}

(b) Future efforts / compliance

\begin{tabular}{|c|c|c|c|c|c|}
\hline \multirow[t]{2}{*}{ Study 1a } & $r$ & $.20[.07, .32]$ & $-.15[-.27,-.02]$ & $.23[.10, .35]$ & $.27[.15, .39]$ \\
\hline & $s r$ & $.19[.06, .31]$ & $-.11[-.24, .02]$ & $.14[.01, .26]$ & $.11[-.03, .24]$ \\
\hline \multirow[t]{2}{*}{ Study $1 \mathrm{~b}$} & $r$ & $.08[-.04, .20]$ & $-.23[-.34,-.12]$ & $.26[.15, .37]$ & $.30[.18, .40]$ \\
\hline & $s r$ & $.12[.00, .24]$ & $-.06[-.18, .06]$ & $.11[-.01, .22]$ & $.14[.02, .26]$ \\
\hline \multirow[t]{2}{*}{ Study $2 a$} & $r$ & $.19[.08, .30]$ & $-.21[-.32,-.10]$ & $.21[.10, .32]$ & $.13[.04, .24]$ \\
\hline & $s r$ & $.13[.01, .24]$ & $-.17[-.28,-.06]$ & $.11[-.01, .22]$ & $.03[-.09, .14]$ \\
\hline \multirow[t]{2}{*}{ Study $2 b$} & $r$ & $.12[.00, .23]$ & $-.16[-.27,-.05]$ & - & - \\
\hline & $s r$ & $.15[.04, .26]$ & $-.19[-.30,-.07]$ & & \\
\hline \multicolumn{2}{|l|}{ Meta-analytic } & $.15[.09, .20]$, & $-.19[-.25,-.13]$, & $.23[.17, .30]$, & $.23[.13, .33]$, \\
\hline \multicolumn{2}{|l|}{ estimate for $\mathrm{r}$} & $Z=4.82, p<.001$ & $Z=-6.29, p<.001$ & $Z=6.65, p<.001$ & $Z=4.22, p<.001$ \\
\hline \multicolumn{2}{|l|}{ Meta-analytic } & $.15[.09, .20]$, & $-.14[-.19,-.08]$ & $.12[.05, .19]$, & $.09[.02, .16]$ \\
\hline \multicolumn{2}{|l|}{ estimate for $\mathrm{sr}$} & $Z=4.78, p<.001$ & $\mathrm{Z}=-4.45, \mathrm{p}<.001$ & $\mathrm{Z}=3.27, \mathrm{p}=.001$ & $\mathrm{Z}=2.50, \mathrm{p}=.013$ \\
\hline
\end{tabular}


Table 9. Results of eight mini-meta (random effects models) for the Pearson correlation $(r)$ and semi-partial correlations ( $s r$ ) between (a) Past efforts/compliance and (b) Future efforts/compliance and (i) Pathogen disgust, (ii) Psychological reactance, (iii) Care values, and (iv) Perspective-taking. Semi-partial correlations are based on the results of the multiple regression analyses. All tests of heterogeneity were non-significant.

However, results for semi-partial correlations paint a different picture. First, perspective-taking is no longer a significant predictor of past compliance, but only of future compliance. Moreover, correlations coefficients for care values and perspective-taking were no longer the highest: correlations were in the same order of magnitude for care values than for pathogen disgust and psychological reactance, and quite low (<.10) for perspective-taking. This suggests that, compared to the effect of pathogen disgust and psychological reactance, the effect of care values and perspective-taking was for a great part explainable by other variables. On the contrary, the overall effect of Pathogen Disgust seemed mostly unaffected by the introduction of other variables, suggesting that its effect is not explained by these other variables.

The effect of perspective-taking on past and future compliance was particularly low for Study 2a, compared to Studies $1 \mathrm{a}$ and $1 \mathrm{~b}$. What could explain this difference? A first possible explanation is the nature of our sample: two US samples in Studies 1a and 1b, and a French sample for Study 2a. However, it is not clear why this should make a difference to the relationship between perspective-taking and compliance. A second explanation might be that Study 2a included fewer predictors than Studies 1a and 1b. However, this seems unlikely, because the zero-order correlations for perspective-taking were also smaller in Study 2a. A 
third explanation might be timing: as mentioned earlier, Studies 1a and 1 were conducted in the middle of the first wave, while Study 2a was conducted between the first and second French waves, at a time where victims of COVID-19 were far fewer and less present and salient in medias. In absence of actual persons to take the perspective of, perspective-taking might have been less likely to motivate compliance.

Overall, results suggest that health behaviors are partly driven by participants' tendency to experience disgust towards pathogens $\left(\mathrm{H} 4^{*}\right)$ and psychological reactance $(\mathrm{H} 5)$. However, we didn't find a significant effect of fear. Furthermore, although empathic concern correlated with compliance, its predictive power was no longer significant when controlling for related constructs such as care values and perspective-taking. These results stress the importance of considering the effect of different emotion categories in decision-making beyond (positive or negative) affect (see also Lerner \& Keltner, 2000). Although reactance, disgust, empathy, and fear sensitivity would all trigger negative affective reactions in the context of the COVID-19 pandemic, only reactance and disgust seemed to predict health behavior when all of these different emotions were taken into account.

Other-regarding cognitive traits such as moral values regarding caring about others (H2) were found to predict participants' efforts to comply with official recommendations. However, this effect was particularly weak in Study 2a. Again, this might potentially be explained by the lack of salient actual or potential victims at the time Study 2a was conducted.

Finally, we found no significant effect of participants' beliefs in conspiracy theories or pseudoscience on health behavior (H1). These results again suggest that cognitive factors might be less relevant than affective factors in motivating health behaviors during the COVID-19 pandemic. However, it is important to note that we measured participants' dispositions towards 
conspiracist thinking, but not their beliefs in COVID-19 conspiracy theories in particular. Thus, it could be that only the latter, but not the former, is related to health behaviors (see Imhoff \& Lamberty, 2020).

One limitation to our results is that the effect we found for self-reported compliance did not extend for the most part to our attempts at measuring 'actual' behavior (with the exception of Pathogen Disgust predicting voting behavior three out of four times). This might be because people are people are bad at estimating their behavior of that our measures of self-report are too dependent on participants' own estimate of what counts as 'enough' compliance. But it might also be due to the fact that the very same behavior can be construed very differently by various participants. Voting might seem reckless to certain persons but a civil duty to others, while going to the restaurant might be seen as selfish and inconsiderate by certain participants or as an act of solidarity towards restaurateurs by others. More generally, people can vary as to what they perceive as risky in the context of the COVID-19 pandemic, making the use of such indicators difficult.

By testing a comprehensive set of relevant traits, our studies contribute to our understanding of the psychology underlying health behaviors during the COVID-19 pandemic. More generally, our results suggest a role for affective factors in motivating behavior. Pathogen disgust and psychological reactance are both affective traits, and moral values are strongly connected to emotions, or perhaps even emotional in nature (Haidt, 2001; Prinz, 2007). Thus, all the predictors identified in our studies share some connection to affects. Conversely, epistemic and cognitive traits seemed to play a more modest role in motivating health behaviors. 
Despite limitations, we hope that our results could have practical implications in the future. Recent research suggests that emphasizing caring for others can foster good practices in the context of the COVID-19 outbreak (Jordan, Yoeli \& Rand, 2020). However, we are not aware of any effort to consider people's psychological reactance and disgust towards pathogens to foment health behaviors.

Past research suggests that triggering people's disgust towards pathogens (e.g., using visual stimuli) can improve health behaviors such as hand-washing (Wiles, Roberts, \& Schmidt, 2015; see also Wilson, Jacob \& Powell, 2011). Regarding psychological reactance, many studies have investigated its role in the context of health communication (see Miron \& Behm, 2015; Steindl et al., 2015). Several strategies have been shown to effectively reduce reactance against health recommendations, for example: using inoculation messages (Richards \& Banas, 2015), narratives (Moyer-Gusé \& Nabi, 2009), framing messages in terms of gains instead of losses (Cho \& Sands, 2011; Shen, 2015), or having laypeople communicate recommendations instead of experts (Förg et al., 2007). All these are promising avenues for future research in the context of health recommendations during the COVID-19 pandemic. However, note that much work is needed for research like the one presented here to be translated into policy.

\section{Acknowledgements}

This work was funded by a SNSF Eccellenza Professorial Fellowship grant attributed to Florian Cova for his project "Eudaimonic emotions and the (meta-)philosophy of well-being" (181083). 


\section{References}

Abdelrahman, M. (2020). Personality Traits, Risk Perception, and Protective Behaviors of Arab Residents of Qatar During the COVID-19 Pandemic. International Journal of Mental Health and Addiction, (Merson 2006). https://doi.org/10.1007/s11469-020-00352-7

Ahorsu, D. K., Lin, C.-Y., Imani, V., Saffari, M., Griffiths, M. D., \& Pakpour, A. H. (2020). The Fear of COVID-19 Scale: Development and Initial Validation. International Journal of Mental Health and Addiction, 1. https://doi.org/10.1007/S11469-020-00270-8

Alper, S., Bayrak, F., \& Yilmaz, O. (2020). Psychological correlates of COVID-19 conspiracy beliefs and preventive measures: Evidence from Turkey. Current Psychology, 110. https://doi.org/10.1007/s12144-020-00903-0

Ames, D. R., Rose, P., \& Anderson, C. P. (2006). The NPI-16 as a short measure of narcissism. Journal of Research in Personality, 40(4), 440-450.

Anderson, R. M., Heesterbeek, H., Klinkenberg, D., \& Hollingsworth, T. D. (2020). How will country-based mitigation measures influence the course of the COVID-19 epidemic? The Lancet, 395(10228), 931-934.

Bhanot, S. (2020). Why are people ignoring expert warnings? - Psychological reactance. Behavioral scientist.

Byrd, N., \& Bialek, M. (2020, July 23rd). Your Health vs. My Liberty: Philosophical beliefs dominated reflection and identifiable victim effects when predicting public health recommendation compliance. https://doi.org/10.31234/osf.io/5tjaf 
Chan, E. Y. (2020). Moral foundations underlying behavioral compliance during the COVID19 pandemic. Personality and Individual Differences, 110463. https://doi.org/10.1016/j.paid.2020.110463

Cho, H., \& Sands, L. (2011). Gain- and Loss-Frame Sun Safety Messages and Psychological Reactance of Adolescents. Communication Research Reports, 28(4), 308-317. https://doi.org/10.1080/08824096.2011.616242

Cichocka, A., Marchlewska, M., \& de Zavala, A. G. (2016). Does Self-Love or Self-Hate Predict Conspiracy Beliefs? Narcissism, Self-Esteem, and the Endorsement of Conspiracy Theories. Social Psychological and Personality Science, 7(2), 157-166. https://doi.org/10.1177/1948550615616170

Davis, M. H. (1983). A Mulitdimensional Approach to Individual Differences in Empathy. Journal of Personality and Social Psychology, 44(1), 113-126. https://doi.org/10.1037/0022$\underline{3514.44 .1 .113}$

Epstein, S., Pacini, R., Denes-Raj, V., \& Heier, H. (1996). Individual differences in intuitiveexperiential and analytical-rational thinking styles. Journal of Personality and Social Psychology, 71(2), 390-405.

Erceg, N., Ružojčić, M., \& Galić, Z. (2020). Misbehaving in the Corona crisis: The role of anxiety and unfounded beliefs. Current Psychology, 1-10. https://doi.org/10.1007/s12144020-01040-4

Freeman, D., Waite, F., Rosebrock, L., Petit, A., Causier, C., East, A., ... Lambe, S. (2020). Coronavirus conspiracy beliefs, mistrust, and compliance with government guidelines in England. Psychological Medicine, 1-13. https://doi.org/10.1017/S0033291720001890 
Förg, M., Jonas, E., Traut-Mattausch, E., Heinemann, F., \& Frey, D. (2007). Vertrauen Bürger in der politischen Reformdiskussion noch der Meinung von Experten?. Wirtschaftspsychologie, (4), 35-45.

Fuhrer, J., \& Cova, F. (2020). "Quick and dirty": Intuitive cognitive style predicts trust in Didier Raoult and his hydroxychloroquine-based treatment against COVID-19. Judgment \& Decision Making, 15(6).

Garrett, R. K., \& Weeks, B. E. (2017). Epistemic beliefs' role in promoting misperceptions and conspiracist ideation. PloS One, 12(9).

Graham, J., Nosek, B. A., Haidt, J., Iyer, R., Koleva, S., \& Ditto, P. H. (2011). Mapping the moral domain. Journal of Personality and Social Psychology, 101(2), 366-385. https://doi.org/10.1037/a0021847

Haidt, J. (2001). The emotional dog and its rational tail: a social intuitionist approach to moral judgment. Psychological Review. Retrieved from http://psycnet.apa.org/journals/rev/108/4/814/

Harper, C. A., Satchell, L. P., Fido, D., \& Latzman, R. D. (2020). Functional Fear Predicts Public Health Compliance in the COVID-19 Pandemic. International Journal of Mental Health and Addiction, 1. https://doi.org/10.1007/s11469-020-00281-5

Hong, S. M., \& Faedda, S. (1996). Refinement of the Hong psychological reactance scale. Educational and Psychological Measurement, 56(1), 173-182. 
Hummel, D., \& Maedche, A. (2019). How effective is nudging? A quantitative review on the effect sizes and limits of empirical nudging studies. Journal of Behavioral and Experimental Economics, 80, 47-58.

Imhoff, R., \& Lamberty, P. (2020). A Bioweapon or a Hoax? The Link Between Distinct Conspiracy Beliefs About the Coronavirus Disease (COVID-19) Outbreak and Pandemic Behavior. Social Psychological and Personality Science. https://doi.org/10.1177/1948550620934692

Iyer, R., Koleva, S., Graham, J., Ditto, P., \& Haidt, J. (2012). Understanding libertarian morality: The psychological dispositions of self-identified libertarians. PloS One, 7(8).

Jensen, U. T. (2020). Is self-reported social distancing susceptible to social desirability bias? Using the crosswise model to elicit sensitive behaviors. Journal of Behavioral Public Administration, 3(2). https://doi.org/10.30636/jbpa.32.182

Jolley, D., \& Douglas, K. M. (2014a). The effects of anti-vaccine conspiracy theories on vaccination intentions. PLoS One, 9, e89177. doi: 10.1371/journal.pone.0089177

Jordan, J., Yoeli, E., \& Rand, D. G. (2020, April 3rd). Don't get it or don't spread it? Comparing self-interested versus prosocially framed COVID-19 prevention messaging. https://doi.org/10.31234/osf.io/yuq7x

Kelland, K., Revell, M. (2020). Explainer: Pandemic behavior - Why people don't play by the rules. Reuters. 
Kramer, M. D., Patrick, C. J., Hettema, J. M., Moore, A. A., Sawyers, C. K., \& Yancey, J. R. (2020). Quantifying dispositional fear as threat sensitivity: Development and initial validation of a model-based scale measure. Assessment, 27(3), 533-546.

Lantian, A., Muller, D., Nurra, C., \& Douglas, K. M. (2016). Measuring belief in conspiracy theories: Validation of a French and English single-item scale. International Review of Social Psychology, 29(1), 1-14.

Lazarus, R. S. (1991). Emotion and adaptation. New York: Oxford University Press.

Lerner, J. S., \& Keltner, D. (2000). Beyond valence: Toward a model of emotion-specific influences on judgement and choice. Cognition \& Emotion, 14(4), 473-493. https://doi.org/10.1080/026999300402763

Lewandowsky, S., Oberauer, K., \& Gignac, G. E. (2013). NASA faked the moon landing Therefore, (climate) science is a hoax: An anatomy of the motivated rejection of science. Psychological Science, 24, 622-633. doi: 10.1177/0956797612457686

Luttrell, A., \& Petty, R. E. (2020). Evaluations of Self-Focused Versus Other-Focused Arguments for Social Distancing: An Extension of Moral Matching Effects. Social Psychological and Personality Science, 1-9. https://doi.org/10.1177/1948550620947853

Marinthe, G., Brown, G., Delouvée, S., \& Jolley, D. (2020). Looking out for myself: Exploring the relationship between conspiracy mentality, perceived personal risk, and COVID-19 prevention measures. British Journal of Health Psychology, 25(4), 957-980. https://doi.org/10.1111/bjhp.12449 
Majima, Y. (2015). Belief in pseudoscience, cognitive style and science literacy. Applied Cognitive Psychology, 29(4), 552-559.

Menard, S. (2011). Applied Logistic Regression Analysis. Applied Logistic Regression Analysis. Sage Publications. https://doi.org/10.4135/9781412983433

Miller, C. H., \& Quick, B. L. (2010). Sensation seeking and psychological reactance as health risk predictors for an emerging adult population. Health communication, 25(3), 266-275.

Miller, C. H., Burgoon, M., Grandpre, J. R., \& Alvaro, E. M. (2006). Identifying principal risk factors for the initiation of adolescent smoking behaviors: The significance of psychological reactance. Health communication, 19(3), 241-252.

Miron, A. M., \& Brehm, J. W. (2006). Reactance Theory - 40 Years Later. Zeitschrift Für Sozialpsychologie, 37(1), 9-18. https://doi.org/10.1024/0044-3514.37.1.9

Moyer-Gusé, E., \& Nabi, R. L. (2010). Explaining the Effects of Narrative in an Entertainment Television Program: Overcoming Resistance to Persuasion. Human Communication Research, 36(1), 26-52. https://doi.org/10.1111/j.1468-2958.2009.01367.x

Nilsson, S., Buchholz, M., \& Thunberg, G. (2012). Assessing Children's Anxiety Using the Modified Short State-Trait Anxiety Inventory and Talking Mats: A Pilot Study. Nursing Research and Practice, 2012, 1-7. https://doi.org/10.1155/2012/932570

Nowak, B., Brzóska, P., Piotrowski, J., Sedikides, C., Żemojtel-Piotrowska, M., \& Jonason, P. K. (2020). Adaptive and maladaptive behavior during the COVID-19 pandemic: The roles of Dark Triad traits, collective narcissism, and health beliefs. Personality and Individual Differences, 167, 110232. https://doi.org/10.1016/j.paid.2020.110232 
Oliver, J. E., \& Wood, T. J. (2014). Medical conspiracy theories and health behaviors in the United States. JAMA Internal Medicine, 174, 817-818. doi:

10.1001/jamainternmed.2014.190

Pennycook, G., \& Rand, D. G. (2019). Lazy, not biased: Susceptibility to partisan fake news is better explained by lack of reasoning than by motivated reasoning. Cognition, 188, 39-50.

Pfattheicher, S., Nockur, L., Böhm, R., Sassenrath, C., \& Petersen, M. B. (n.d.). The emotional path to action: Empathy promotes physical distancing and wearing of face masks during the COVID-19 pandemic. Psychological Science.

Prinz, J. (2007). The emotional construction of morals. New York: Oxford University Press.

Qian, K., \& Yahara, T. (2020). Mentality and behavior in COVID-19 emergency status in Japan: Influence of personality, morality and ideology. PLoS ONE, 15(7 July), e0235883. https://doi.org/10.1371/journal.pone.0235883

Romer, D., \& Jamieson, K. H. (2020). Conspiracy theories as barriers to controlling the spread of COVID-19 in the U.S. Social Science \& Medicine, 263, 113356. https://doi.org/10.1016/J.SOCSCIMED.2020.113356

Richards AS, Banas JA. Inoculating against reactance to persuasive health messages. Health Commun. 2015;30(5):451-60. Doi: 10.1080/10410236.2013.867005. Epub 2014 June 27th. PMID: 24972121.

Schönbrodt, F. D., \& Perugini, M. (2013). At what sample size do correlations stabilize? Journal of Research in Personality, 47(5), 609-612. 
Shen, L. (2015). Antecedents to Psychological Reactance: The Impact of Threat, Message Frame, and Choice. Health Communication, 30(10), 975-985.

https://doi.org/10.1080/10410236.2014.910882

Shook, N. J., Sevi, B., Lee, J., Oosterhoff, B., \& Fitzgerald, H. N. (2020). Disease avoidance in the time of COVID-19: The behavioral immune system is associated with concern and preventative health behaviors. PLoS ONE, 15(August 8th), 1-15. https://doi.org/10.1371/journal.pone.0238015

Steindl, C., Jonas, E., Sittenthaler, S., Traut-Mattausch, E., \& Greenberg, J. (2015).

Understanding Psychological Reactance: New Developments and Findings. Zeitschrift fur Psychologie, 223(4), 205-214. https://doi.org/10.1027/2151-2604/a000222

Tybur, J. M., Lieberman, D., \& Griskevicius, V. (2009). Microbes, mating, and morality: individual differences in three functional domains of disgust. Journal of Personality and Social Psychology, 97(1), 103.

Van Bavel, J. J., Baicker, K., Boggio, P., Capraro, V., Cichocka, A., Crockett, M., ... Willer, R. (in press). Using social and behavioural science to support COVID-19 pandemic response. Nature Human Behavior.

Van der Linden, S. (2015). The conspiracy-effect: Exposure to conspiracy theories (about global warming) decreases pro-social behavior and science acceptance. Personality and Individual Differences, 87, 171-173. doi: 10.1016/j.paid.2015.07.045

Van Mulukom, V., Pummerer, L., Alper, S., Bai, H., Cavojova, V., Farias, J. E. M., ... Zezelj, I. (2020, November 14). Antecedents and consequences of COVID-19 conspiracy beliefs: a rapid review of the evidence. https://doi.org/10.31234/osf.io/u8yah 
Wiest, B. (2020). The psychological reason why some people aren't following COVID-19 quarantine orders. Forbes.

Wiles, L. L., Roberts, C., \& Schmidt, K. (2015). Keep it clean: a visual approach to reinforce hand hygiene compliance in the emergency department. Journal of Emergency Nursing, $41(2), 119-124$.

Wilson, S., Jacob, C. J., \& Powell, D. (2011). Behavior-change interventions to improve hand-hygiene practice: a review of alternatives to education. Critical Public Health, 21(1), $119-127$. 